\title{
O ATLETA E A PUBLICIDADE: reflexões acerca dos contratos publicitários esportivos expostos nas obras literárias de Harlan Coben
}

\author{
Laís Cristune Alexandre dos Santos' \\ André Mendes Capraro²
}

\section{RESUMO}

Harlan Coben, escritor estadunidense de romances policiais, utiliza elementos esportivos como constituintes de sua estrutura narrativa. Desse modo, procuramos identificar as relações estabelecidas entre o meio esportivo e a publicidade expostas nas obras "Quebra de Confiança" (2011) e "Jogada Mortal" (2012), primeiras tramas da série "Myron Bolitar", por meio da análise dos personagens Christian Steele e Duane Richwood. Para tal, utilizaram-se os preceitos acerca da análise literária proposta por Antonio Candido (2000), que considera texto e contexto como constructos das narrativas, constatando-se que Coben retrata tais personagens como garotos-propaganda sujeitos às efemeridades presentes tanto no meio esportivo, quanto na permanência relacionada aos conglomerados de mídia, bem como pontua empresas de produtos esportivos de alto impacto neste segmento mercadológico dos anos 1990.

Palavras-chave: Esportes. Literatura. Atletas. Publicidade como Assunto.

1 Mestranda em Educação Física. Universidade Federal do Paraná (UFPR). Curitiba/Paraná, Brasil.

E-mail: lais.cris@hotmail.com

2 Doutor em História. Professor da Universidade Federal do Paraná (UFPR). Curitiba/Paraná, Brasil.

E-mail: andrecapraro@onda.com.br

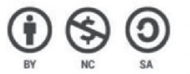

Este texto está publicado sob uma licença Creative Commons Atribuição NãoComercial-CompartilhaIgual - CC BY NC AS

Mais detalhes em: https://br.creativecommons.org/licencas/ 
ATHLETE AND ADVERTISING: reflections of advertising contracts sports exposed in literary works by Harlan Coben

\begin{abstract}
Harlan Coben, an american crime writer, uses sports elements as constituents of its narrative structure. We sought to identify the relations between the sports field and the exposed advertising in the works "Deal Breaker" (2011) and "Drop Shot" (2012), first plot of the series "Myron Bolitar", through the analysis of characters Christian Steele and Duane Richwood. For this, we used the precepts about literary analysis proposed by Antonio Candido (2000), which considers text and context as constructs narratives, if noting that Coben portraying such characters as poster boys subject to the ephemera present both in sports, as the permanence related to media conglomerates and punctuates companies sporting goods of high impact marketing in this segment of the 1990s.
\end{abstract}

Keywords: Sports. Literature. Athletes. Advertising as Topic.

ATLETA Y PUBLICIDAD: reflexiones de contratos de publicidad deportiva expuestas a las obras literarias de Harlan Coben

\title{
RESUMEN
}

Harlan Coben, escritor crimen en Estados Unidos, utiliza elementos deportivos como constituyentes de su estructura narrativa. Hemos tratado de identificar las relaciones entre el campo de deportes y el medio de la publicidad expuesta en las obras "Breach" (2011) y "Juego Mortal" (2012), el primer argumento de la serie "Myron Bolitar", a través del análisis de personajes Christian Steele y Duane Richwood. Para ello, hemos utilizado los preceptos sobre el análisis literario propuesto por Antonio Candido (2000), que consideran que el texto y el contexto como construcciones narrativas, señalando que si Coben retratar personajes tales como los niños de carteles sujetos a lo efímero presente tanto en los deportes, como la permanencia relacionada con los conglomerados de medios y puntúa las compañías de artículos deportivos de alto impacto de comercialización en este segmento de los años 1990.

Palabras clave: Deportes. Literatura. Atletas. Publicidad como Asunto. 


\section{INTRODUÇÃO ${ }^{3}$}

Na literatura, o romance policial configura-se como um subgênero narrativo exposto pela primeira vez nos contos de Edgar Allan Poe, publicados originalmente durante o século XIX (MASSI, 2011). Os enredos alocados sob essa perspectiva consistem na exposição de uma investigação fictícia que perpassa o enredo da obra (PIRES, 2005) e na representação do detetive-protagonista que elucidará as pistas elucubradas nas histórias, baseado em métodos rigorosamente correspondidos. Esse personagem, portanto, é o responsável pela catarse literária dessa narrativa.

Os romances policiais desde então, têm como característica atrair o leitor para a trama, despertando a curiosidade do mesmo acerca do desfecho da história. Segundo Lins (1947, p.11), "[...] a leitura de um romance policial é uma evasão, uma troca de realidades, é a entrada num universo de natureza anormal, o do crime". Existe, desse modo, a identificação dos leitores com elementos que constituem a estrutura narrativa, usualmente características sociais, como classe social e grupos de identificação, ou aspectos identitários, tais como comportamentos, práticas de lazer e vestuários.

Myron Bolitar é o personagem principal da série de romance policial do escritor estadunidense Harlan Coben, consequentemente os enredos abarcam características do contexto sociocultural do autor. Reiterando os fatores acima citados, a série composta por onze obras, enfoca a atuação profissional de Myron, uma ex-promessa do basquetebol profissional que, devido uma lesão articular, teve de desistir da carreira esportiva prematuramente. O protagonista então, forma-se em direito pela Universidade de Harvard e trabalha por um breve período para o $\mathrm{FBI}$. A carreira como investigador do $\mathrm{FBI}$ se encerra e Myron passa a atuar profissionalmente como agente esportivo, gerenciando atletas de variadas modalidades.

No entanto, em determinadas tramas os atletas agenciados por Bolitar envolvem-se em casos como assassinatos, perseguições e desaparecimentos, levando o personagem a utilizar sua experiência profissional para investigar as situações apresentadas, com o intuito de proteger a integridade pública de seus clientes. Nessa instância, o objetivo do presente artigo é analisar as relações estabelecidas entre o meio publicitário e o meio esportivo manifestadas nas duas primeiras obras da série de romance policial Myron Bolitar, de Harlan Coben.

As obras da série concentram suas publicações nos anos 1990 e 2000, refletindo características dos Estados Unidos nesse período ${ }^{4}$. Fernanda Massi (2011, p. 134), ao estudar romances policiais tradicionais e romances policiais contemporâneos ${ }^{5}$, constatou

3 A pesquisa que resultou neste artigo contou com apoio financeiro da Agência Capes.

4 A tradução das obras da série para o português brasileiro ocorreu a partir de 2008, iniciada pela editora ARX. Posteriormente os direitos de publicação foram adquiridos pela editora Arqueiro, atual responsável pela comercialização das tramas de Harlan Coben.

5 De acordo com Massi (2011), não existem diferenças substanciais com relação à romances policiais tradicionais, no qual podemos alocar autores como Agatha Christie e Sir Arthur Conan Doyle, e romances policiais contemporâneos, como os do autor Dan Brown por exemplo. Há, no entanto, o que pode ser definido como 
que o segundo também enfoca o enredo no assassinato e passa a destacar aspectos de relevância social, tais como corrupção, falta de ética, impunidade, hipocrisia, entre outros. Harlan Coben, enquanto escritor contemporâneo, abarca tais características na série de Myron Bolitar, estabelecendo elementos escusos presentes nas negociações esportivas (como chantagens referentes ao passado dos atletas), rivalidades entre atletas, diplomacia nos esportes, assédio moral e profissional, extorsões financeiras, entre outros.

Nosso escopo de análise para o presente artigo concentrará as duas primeiras obras da série, os livros "Quebra de Confiança" e "Jogada Mortal", publicadas respectivamente em 2011 e 2012 no Brasil $^{6}$. Em tais enredos, Harlan Coben descreve de forma literária o lado obscuro do meio esportivo, com ênfase na espetacularização a que as modalidades estão sujeitas, do mesmo modo que o protagonista apresenta delineamentos iniciais acerca de sua personalidade e de sua fase de constituição como agente esportivo, possibilitando que as narrativas contenham ênfases à caracterização da figura dramática.

Salientamos que, nas obras analisadas, Harlan Coben apropria-se de características do esporte-espetáculo para delinear as modalidades que elege para representar artisticamente, aspecto que, segundo Candido (2000), denota a autonomia criativa do autor. Enquanto entretenimento, Douglas Kellner (2004) localiza o espetáculo como um fenômeno da cultura da mídia e o esporte como um meio propício a representação espetacularizada de valores sociais, por meio dos megaeventos. Segundo o autor, "as empresas estão dispostas a investir grandes verbas para terem seus produtos associados a esses eventos" (KELLNER, 2004, p. 7). Por esta lógica, Bourdieu (1983, p. 9), “o esporte-espetáculo apareceria mais claramente como uma mercadoria de massa e a organização de espetáculos esportivos como um ramo entre outros do show business".

\section{MATERIAL E MÉTODOS}

Como descrito anteriormente, o escopo de análise deste artigo encerrará as duas primeiras obras da série de romance policial "Myron Bolitar", do escritor Harlan Coben: "Quebra de Confiança" (2011) e "Jogada Mortal" (2012), devido ao destaque à relação entre atletas e produtos que as obras apresentam.

Para tal intento, elegemos como método de análise a proposta acerca da abordagem literária de Antonio Candido (2000), que considera como fatores estruturantes da obra o texto e o contexto. O primeiro fator representa a autonomia do escritor enquanto componente que está sujeito às influências do meio social em está inserido, mas que, ao mesmo tempo, através de sua obra, influência o ambiente. Desse modo, existe uma amalgama entre a estética literária e elementos históricos e sociais manifestos nas tramas, e a integridade da obra não permite uma análise de tais fatores dissociados.

um deslocamento no gênero, cujo as características destacadas nos enredos tradicionais, atualmente passam a ter uma perspectiva secundária. 
Devido à presença da historicidade como constituinte da literatura, segundo Candido (2000) emergem diferentes modalidades de estudos sobre as obras. Destas modalidades, empregaremos o segundo tipo destacado pelo autor, que compreende: "Estudos que procuram verificar a medida em que as obras espelham ou representam a sociedade [...] consistindo basicamente em estabelecer correlações entre os aspectos reais e os que aparecem no livro" (CANDIDO, 2000, p.10).

Na série literária "Myron Bolitar", o protagonista e agente esportivo da série em pauta, pode ser considerado a principal figura dramática de autoria de Harlan Coben, uma vez que o escritor é o único até o momento atual, em 2016, a ter recebido a chamada "Trinca de Ases" da literatura policial norte-americana, constituída pelo prêmio Anthony, o prêmio Shamus e o prêmio Edgar Allan Poe, todos por obras da série "Myron Bolitar". O autor ainda possui outras publicações independentes, enquadradas no gênero literário em discussão, bem como outra série, intitulada "Mickey Bolitar", tramas cujo personagem principal é o sobrinho de Myron Bolitar.

A versatilidade do autor em relação a seus enredos destaca-se pela adaptação de algumas tramas de Coben para o cinema e para a televisão, tais como, "Não Conte a Ninguém"7 (2006) e "The Five" (2016), respectivamente. O autor, que já figurou como número um na lista de livros mais vendidos do jornal estadunidense The New York Times, soma mais de 60 milhões de exemplares impressos no mundo e, no Brasil, contabiliza a marca de mais de 1 milhão de cópias vendidas ${ }^{8}$, dado relevante, uma vez que a média de livros lidos pelo brasileiro por ano é de 4,54, sendo que desses 1,91 são livros lidos completamente e 2,64 são livros lidos parcialmente ${ }^{9}$.

Aproximando-nos da área da comunicação, compreende-se que a publicidade é composta por um conjunto de recursos utilizados para tornar algo público (AGÊNCIA FIRMA, 2016). Nesse prisma, emergem os garotos-propaganda ${ }^{10}$, responsáveis por promover a interação produto-público, entre os quais os atletas destacam-se. Alexón Gabriel João (2006) indica as características do garoto-propaganda: a celebridade, a credibilidade, a estética, a seriedade, a formalidade, a autoridade e a fidelização, os dois últimos em menor grau de impacto sobre os agentes mencionados.

7 Longa metragem produzido pela indústria cinematográfica francesa, vencedor dos prêmios Lumière e de quatro Césars, equivalentes franceses aos prêmios norte-americanos Globo de Ouro e Oscar, respectivamente.

8 Dado referente ao ano de 2014.

9 Dados divulgados em maio de 2016 por meio da $4^{\circ}$ edição da pesquisa "Retratos da Leitura no Brasil", realizada pelo Instituto Pró-Livro (IBL), com apoio da Associação Brasileira de Editores de Livros Escolares (Abrelivros), da Câmara Brasileira do Livro (CBL) e do Sindicato Nacional dos Editores de Livros (SNEL). O estudo foi dirigido pelo Ibope Inteligência e registrou 5 mil entrevistados, considerando a população alfabetizada e não alfabetizada, maior de 5 anos de idade, nas cinco regiões brasileiras. Para registrar a média de livros lidos pelo brasileiro, foram considerados na pesquisa livros indicados pela escola, que incluíam livros didáticos, e livros lidos por vontade própria, que incluíam a Bíblia. Disponível em: http://www.snel.org.br/wp-content/uploads/2016/06/ Pesquisa_Retratos_da_Leitura_no_Brasil___4.pdf.

10 O termo garoto-propaganda emerge, segundo Marcondes (2001), no período em que as peças publicitárias eram produzidas ao vivo, visando ainda os aparelhos televisores em preto e branco. A expressão, de acordo com o autor, denominava as garotas da propaganda, que declamavam e demonstravam os benefícios dos produtos anunciados, sem a existência do videotape. 
Por meio dos aspectos citados, abordaremos personagens-atletas da série literária em pauta, retratados na série: Christian Steele, atleta de futebol americano evidenciado na obra "Quebra de Confiança", e Duane Richwood, tenista profissional, personagem de "Jogada Mortal". Ambas as figuras dramáticas elucidam as características de garotos-propaganda, candidatos a contratos publicitários relevantes de marcas esportivas características, como a Nike, por exemplo. Ao longo dos dois enredos, outras marcas, de renome no cenário dos anos 1990, são pontuadas, como Reebok e Heineken, expondo nas narrativas literárias a perspectiva de mercado que circunda o meio esportivo do período. Analisaremos os personagens de acordo com as características do garoto-propaganda indicadas por João (2006), citadas anteriormente.

Com relação ao marketing, Kotler e Armstrong (2003, p. 3) destacam que, "o marketing é considerado um processo administrativo e social para a satisfação de necessidades e desejos através da criação, oferta e troca de produtos". Assim, a publicidade é um dos recursos que compõem a ação de marketing, presente também em sua manifestação no esporte, o marketing esportivo. Este artigo focará a perspectiva da relação entre esporte e sua manifestação pública ${ }^{11}$.

\section{RESULTADOS E DISCUSSÃO}

Guy Debord (1931-1994), em “A Sociedade do Espetáculo (2003) ${ }^{12}$, indica em sua quarta proposição, que os espetáculos consistem em não apenas "[...] um conjunto de imagens, mas uma relação social entre pessoas, mediatizada por imagens (2003, p. 14). E, dadas as perspectivas de Bourdieu (1983) e Kellner (2004) citadas anteriormente, acerca dos espetáculos esportivos, em que o esporte se demonstra como um campo profícuo ao desenvolvimento de valores sociais apreciados pelos grupos que consomem tais práticas, entende-se que a edição esportiva ou edição das imagens relacionadas aos esportes, perscrutam as atividades cotidianas e as relações entre pessoas.

Mauro Betti (1997) por sua vez, ao discorrer acerca do esporte-espetáculo, destaca o anúncio publicitário, associado aos esportes e seus elementos subsequentes, como artifício capaz de sintetizar as emoções incutidas no meio. Desse modo, a indústria passou a cooptar o esporte como componente estrutural e lucrativo, dado o potencial de oferta "da popularidade dos astros esportivos, da constante recepção de informações e imagens sobre o esporte, e da combinação do sucesso com a imagem do produto" (BETTI, 1997, p. 34).

No primeiro livro analisado Christian Steele é apresentado no enredo como um garoto branco, quarterback, grande promessa do futebol americano dados os resultados que obtive em anos anteriores às tramas, prestes a fechar contrato com um time de alta representatividade no cenário da modalidade e "[...] como se isso não bastasse, o garoto era

11 Para mais estudos sobre marketing esportivo ver: Giovanni, Gebara e Proni (1995); Proni (1998); Dias et al (2009); Pozzi (2000); Vlastuin, Almeida e Marchi Júnior (2008).

12 A primeira publicação da obra data do ano de 1967. 
o sonho dourado de qualquer patrocinador. Aluno exemplar, bonito, articulado, educado" (COBEN, 2011, p. 8). Duane Richwood, por sua vez, é representado como um jovem negro, tenista profissional, que fugiu de casa aos quinze anos de idade e cresceu nas ruas da cidade de Nova York, e que, com dedicação, chegou à sua primeira participação no Aberto de Tênis dos Estados Unidos, atuando como "sangue novo e fresco" na modalidade por ser "[...] carismático, engraçado, um pouco polêmico, mas ainda não odiado" (COBEN, 2012, p. 17).

Nota-se nos enredos, portanto, a representação dos atletas como modelos sociais, celebridades das modalidades nas quais atuam, exemplos de boas condutas que podem figurar como protagonistas de contratos publicitários. Por meio do personagem de Myron, dado sua profissão e papel nas negociações esportivas narradas, percebe-se a dimensão da importância vinculada entre o campo esportivo e a publicidade, representadas nas obras, principalmente por meio da elucidação de jogadores em início de carreira, como exemplifica o seguinte trecho do livro "Jogada Mortal":

[...] A imagem de um atleta era construída mais por essas campanhas publicitárias do que por qualquer outra coisa, incluindo o quão bem ele jogasse e o que a mídia falasse dele. Os atletas passavam a ser definidos pelos produtos que representavam. Quantas pessoas não conheciam Michael Jordan como Air Jordan? A maioria dos torcedores não afirmaria com certeza que Larry Johnson jogava pelo Charlotte Hornets, mas saberia tudo sobre a velinha que ele havia interpretado em um anúncio. A campanha certa poderia fazer uma carreira. A campanha errada poderia destruí-la (COBEN, 2012, p. 16).

No plano da análise, a cultura da mídia, um fenômeno histórico recente, propícia a recepção de imagens em fluxo constante e de fácil acesso (Kellner, 2001, p.27), facilitados pelo aparelho televisor. De acordo com Betti (1997, p. 34), "a televisão modificou a audiência do esporte em todo o mundo, e forçou-o a um papel de dependência, à medida que o tornou menos capaz de subsistir com espectadores ao vivo, dependendo do patrocínio resultante das transmissões televisivas". Portanto, a valorização da imagem a ser difundida passa a ser pauta da discussão dos fornecedores de produtos, bem como a escolha correta do representante que divulgará tal item comercial. Eis o atleta como garoto-propaganda das peças publicitárias.

João (2006), indica que a primeira característica dos garotos-propaganda é a celebridade, que empresta ao produto seu renome, pois “[...] a pessoa célebre é, no imaginário do público, alguém ilustre, com reputação incomum e posição de destaque, normalmente obtida no campo da mídia, da moda ou do esporte" (JOÃO, 2006, p. 45). Tal abordagem evidencia a publicidade como aquele campo que compreende os recursos utilizados para atingir o público alvo, dos quais os atletas emergem como profícuos.

Christian e Duane, são ilustrados como personagens notáveis no futebol americano e no tênis, respectivamente, cujas carreiras prometem ascensões, alcançando o status da celebridade, como por exemplo, nesta passagem do primeiro personagem: "O interesse da imprensa havia ficado maior do que nunca. Ele gostava da atenção, gostava de sair na 
capa da Sports Illustrated, gostava da admiração no rosto das pessoas quando falavam com ele" (COBEN, 2011, p. 35).

Mesmo assim, a credibilidade, segundo fator denotado por João (2006), é requisito prévio para a escolha de um bom garoto-propaganda, uma vez que as características positivas que estejam associadas aos atores-representantes dos comerciais influenciam na identificação do consumidor com os anúncios. Desse modo, um atleta em fase ruim na carreira ou que esteja constantemente envolvido em escândalos, dificilmente é elencado como representante de marcas comerciais, enfatizando a personificação dos tipos dramáticos que tratamos neste artigo, como "bons-moços" e exemplos sociais.

A confiança no atleta reflete na confiabilidade denotada em relação ao produto comercializado. Um atleta de modalidade esportiva " $\mathrm{X}$ ", dificilmente será contratado para anunciar um produto referente à modalidade esportiva " $Y$ ", mas se o produto tem relação com a sua modalidade ou atividades relacionadas, a identificação pelo público alvo e confiabilidade são elevadas, o que leva ao atleta ser uma boa opção publicitária. Nesse sentido, nota-se de acordo com a perspectiva de Antonio Candido (2000), que Harlan Coben incorpora em seus enredos elementos da cultura capitalista e corporativista do contexto estadunidense, ou seja, aspectos sociais externos convertidos em elementos internos à composição do texto. A exemplo, o seguinte trecho:

[...] No seu lugar ao lado da cadeira do juiz, Duane bebia alegremente uma garrafa de água mineral Evian. Ele a segurava de modo que o nome do patrocinador ficasse bem à mostra para as câmeras de TV. Garoto esperto. Sabia como agradar o patrocinador. Pouco antes, Myron havia conseguido um contrato simples com o gigante da indústria de água mineral: durante o Aberto dos Estados Unidos, Duane só beberia Evian em garrafas com rótulo. Em troca, a empresa lhe pagara 10 mil dólares. Isso valia para a água. Myron estava negociando com a Pepsi, o refrigerante que Duane beberia e, com a Gatorade, o isotônico. (COBEN, 2012, p.8)

Do mesmo modo a estética, em sua acepção do belo, demonstra efeitos sobre os consumidores por meio da identificação desses com caraterísticas consideradas harmoniosas nos contextos em que os comerciais se propagam. Atletas comumente representam ideais de saúde, beleza e, na maior parte das peças publicitárias, jovialidade, tributos valorizados pela sociedade do século XXI. Sobre a seriedade, outro caráter indicado por João (2006), a própria constitui-se como a peculiaridade que confere legitimidade ao artigo comercial anunciado, ratificando o valor de agregação do produto.

Amalgamada à seriedade está a formalidade, que define o garoto-propaganda como o representante de um produto ao qual será capaz de atribuir características solenes (JÕ̃O, 2006, p. 47). Na maioria dos casos, jogadores, especialmente os atletas-celebridades do alto rendimento, comumente comprometidos com rotinas de treinamento rigorosas e, por personalidade, respeitosos às regras que instituem seus esportes de origem, tendem a figurar como indivíduos de protagonismo em campanhas desse tipo.

Até aqui, elucidamos características que costumam constituir os atletas eleitos para protagonizar peças publicitárias, assim como suas constantes aparições nos meios 
midiáticos. Essas características são atribuídas aos personagens analisados Christian Steelle e Duane Richwood, de Harlan Coben. No entanto, é importante ressaltar que tais qualidades não são estanques, portanto, não precisam estar todas presentes ao mesmo tempo na produção da peça publicitária.

Em outra esfera de análise, Henry Jenkins (2009), ao discorrer acerca da economia afetiva, a qual, "[...] procura entender os fundamentos emocionais da tomada de decisão do consumidor como uma força motriz por trás das decisões de audiência e compra" (JENKINS, 2009. P. 96). Ou seja, conhecer o público ao qual o produto se destina e os motivos que o levam à aquisição de tal produto, é fundamental no momento da elaboração das peças publicitárias e consequentemente, de seus representantes comerciais. No caso que destacamos, na escolha dos atletas. Essa abordagem representa uma nova ação desenvolvida pelos conglomerados de mídia para atingir o público, na tentativa de moldar as vontades dos consumidores e influenciar as escolhas de aquisição. Levar em conta as características denotadas por João (2006) para garotos-propaganda bem-sucedidos é uma alternativa nesta perspectiva.

Ora, se assim como Betti (1997), indica que as peças publicitárias, enquanto sínteses pragmáticas de produtos a serem comercializados, são capazes de reproduzir a emoção que envolve o esporte; a economia afetiva esclarece, neste caso em particular, que a ação da indústria esportiva ${ }^{13}$ se dá por meio de despertar no consumidor sentimentos e vontades, que podem levar a modificação das preferências de investimentos. Marchi Jr. (2015), caracteriza a emoção como um fator analítico do esporte:

[...] Essa dimensão associa-se às possibilidades que o esporte detém de remeter seu praticante a, por exemplo, situações de desafios e riscos controlados quer sejam eles de ordem construída tecnologicamente, quer sejam eles apresentados de forma primária na natureza. Invariavelmente essas práticas levam o ser humano a um intenso nível de excitação o qual tem por finalidade, no limite, uma contraposição à rotina ou rotinas do cotidiano. (MARCHI JR. 2015, p. 60)

Em uma catarse esportiva, por assim dizer, o atleta representa para o consumidor, características de liberação social, por meio de aspectos que constituem a sua personalidade enquanto agente do meio esportivo, exaltados através da identificação gerada pelas emoções promovidas pelos planos comerciais. Nesse sentido, Betti (1997, p. 161), postula dois tipos de promoção publicitária relacionadas ao esporte: aqueles que vendem o esporte propriamente dito e aqueles que tem o esporte como tema. O primeiro, refere-se à promoção da prática esportiva em si, com anúncios de materiais relacionados e eventos esportivos, enquanto que o segundo aproxima o esporte de outros produtos como alimentos, automóveis, higiene pessoal, acessórios, entre outros.

Em "Quebra de Confiança" e "Jogada Mortal", Crhistian e Duane podem ser enquadrados em tais perspectivas de anúncios, a exemplo o seguinte trecho, em que

13 E não somente a indústria de produtos esportivos, mas também de produtos alimentícios ou estéticos, como o caso das marcas Clear Men, Gillete, Elma Chips e Seara. 
percebemos o destaque para elementos do tênis, mas também de marcas sem relação direta com a prática esportiva:

[...] Os jogadores se posicionaram em quadra. Eles também eram outdoors, porém menores. Duane usava roupas e calçados da Nike. Sua raquete era da marca Head. Logotipos do McDonald's e da Sony enfeitavam as mangas da camisa. Seu adversário usava Reebok. Os logotipos dele eram da Sharp e da Bic. Bic. A empresa de canetas e lâminas de barbear. Como se alguém fosse assistir a uma partida de tênis, ver a marca e comprar uma caneta. (COBEN, 2012, p. 10)

Através dos fatores apresentados até então, podemos constatar que atletas podem se apresentar como profícuos garotos-propaganda, dado às qualidades que possuem e a facilidade de identificação dos valores que os patrocinadores desejam destacar, mas podem ser sujeitos efêmeros, como abordaremos adiante. Esta relação esportista-patrocinador é, provavelmente, a manifestação mais frequente de aproximação entre o meio esportivo e a publicidade, pois atende aos interesses de ambos os polos envolvidos na negociação, ou seja, investe-se no atleta ao mesmo tempo em que se investe na marca.

As redes sociais, enquanto novas mídias, mesmo com a subjetividade na mensuração de visualizações efetivas, ampliam o alcance das peças publicitárias e, a critério de exemplo, após as Olimpíadas do Rio 2016, de acordo com os grupos de Mídia Pixability e Omnicom ${ }^{14}$ (2016), os atletas cujo desempenho foram positivos nos Jogos Olímpicos, com aquisição de medalhas, obtiveram mais repercussão, como os norte-americanos Michael Phelps e Simone Biles e o jamaicano Usain Bolt. Ainda de acordo com os dados divulgados, o comercial mais visualizado foi da marca Under Armour, empresa de roupas e equipamentos esportivos estadunidense, intitulado "Rule Yourself", que apresenta a rotina de treinos do nadador Michael Phelps.

No entanto, atletas não podem ser considerados como garantias de que as peças publicitárias que protagonizam serão sinônimas de sucesso de comercialização. Nesse sentido, chegamos às duas últimas características indicadas por João (2006), a autoridade e a fidelização, ambas oscilantes no caso dos esportistas. A autoridade refere-se ao conhecimento de causa, ou seja, o garoto-propaganda tem conhecimento especializado no que tange ao produto que anuncia, como é o caso de dentistas que protagonizam peças publicitárias sobre cremes dentais.

Quando relacionada aos atletas, a autoridade pode se fazer presente ou não, uma vez que um esportista pode representar marcas de tênis esportivos e demais materiais para prática de modalidades em que atuam, entre outros, do mesmo modo que alguns se apresentam como símbolos de marcas não relacionadas aos esportes, como bebidas alcoólicas e redes de fast food. Já a fidelização, engloba a permanência de um garoto-propaganda como representante de uma marca, muitas vezes dado os resultados positivos obtidos com as propagandas.

14 Disponível em: < http://adnews.com.br/midia/infografico-mostra-quais-marcas-e-atletas-da-rio-2016-maisrepercutiram-nas-redes.html > . Acesso em: 24 de agosto de 2016. 
Tais instâncias, autoridade e fidelização, são inconstantes quando relacionadas aos atletas, principalmente a fidelização, uma vez que, como apresentamos anteriormente, o período de atuação profissional em que o atleta se encontra influencia diretamente seus contratos publicitários. Ou seja, um período de vitórias e ascensão denota a eficácia de alcance positivo do atleta como garoto-propaganda, e desse modo, podemos perceber a efemeridade de atletas como representantes de marcas específicas, dado à oscilação à que esportistas profissionais estão sujeitos, fator que difere no caso de atores e atrizes. A exemplo o jogador brasileiro de futebol Neymar Jr., atleta/celebridade que já foi símbolo das marcas Lupo, Seara, Baruel, Guaraná, Clear, entre outras e, como é possível perceber, são diferentes tipos de indústria, desde a alimentícia até a de moda.

Em raras exceções, porém, é possível que atletas consigam assinar os chamados contratos vitalícios, em que permanecem com a empresa com a qual assinaram permanentemente ou até que o acordo seja violado pelas partes interessadas. No âmbito esportivo, a empresa de maior distinção com relação a este tipo de acordo publicitário é a norte-americana Nike, fundada na década de 1960, cujo foco no mercado consumidor de materiais esportivos, como tênis, roupas e acessórios, já garantiram contrato vitalício com os atletas Michael Jordan, mencionado no livro que analisamos, Lebron James, Ronaldo (Fenômeno), David Beckham, Pelé, entre outros, todos circundados pela fama.

Sobre os períodos negativos das carreiras dos atletas e sua relação com a publicidade, podemos elencar o exemplo do nadador norte-americano Ryan Lochte, que após um escândalo envolvendo um suposto assalto ao atleta e demais colegas da equipe estadunidense, nos Jogos Olímpicos Rio 2016, o qual provou-se uma falsa ocorrência, perdeu seus patrocínios frente ao seu posicionamento considerado imoral para com a situação. $\mathrm{O}$ atleta perdeu patrocínio da empresa Speedo USA, com a qual seu contrato durava cerca de uma década e com a grife Rauph Lauren, que não renovou seu contrato.

Ao realizar a análise dos livros de Harlan Coben, percebe-se que o autor demonstra a instabilidade de seus atletas-personagens com relação aos acordos publicitários ao final dos romances policiais, denotando novamente elementos externos-internos para estruturação do enredo, como indicado por Candido (2000). Tanto Christian Steele, quanto Duane Richwood, provam-se envolvidos nos crimes que ocorrem em seus respectivos enredos, quebrando os contratos que se estabeleceram no enredo.

Por sua vez, Myron Bolitar, o protagonista, é retratado como um agente esportivo que preza por valores éticos em seus negócios, ao contrário das demais agências esportivas expostas nos enredos, como o caso da "TruPro" (agência concorrente a empresa de Myron neste seguimento). O personagem então acaba por ser eficaz enquanto detetive, porém ineficaz no que concerne à manutenção do contrato com seus clientes mais representativos e consequentemente, de seus contratos publicitários.

\section{CONSIDERAÇÕES FINAIS}

Neste artigo analisamos os dois primeiros títulos que compõem a série de literatura policial "Myron Bolitar", de autoria de Harlan Coben: os livros "Quebra de Confiança" 
(2011) e "Jogada Mortal" (2012). Ao utilizarmos dos preceitos da análise literária propostos por Antonio Candido (2000), constatamos que o meio esportivo e a publicidade estão intimamente relacionados, principalmente por meio dos contratos de anúncios publicitários, que denotam a influência do contexto do autor na estruturação de seus enredos e na construção das figuras dramáticas secundárias.

De acordo com as características do garoto-propaganda aplicadas por João (2006), entende-se que para a produção literária, Coben utiliza a representação dos personagens Christian Steele e Duane Richwood como promessas das modalidades esportivas em que atuam, ambas de expressão no cenário estadunidense, através do destaque às características positivas e vantajosas, no que concerne aos garotos-propaganda de peças publicitárias. Porém, o autor também denota a inconstância atribuída aos atletas que ocupam essa posição, intimamente relacionada com seu desempenho efêmero na carreira esportiva e, em alguns casos, na vida privada.

No entanto, tais obras têm suas publicações originais datadas dos anos 1990, contexto no qual as redes sociais não têm a influência sobre o público consumidor que apresentam atualmente. Como destacamos, nos casos positivos e negativos relacionados aos atletas que são garotos-propaganda, as redes sociais influenciam diretamente na relação fornecedor-consumidor, cujo enfoque, assim como demonstrado por Jenkins ao conceituar cultura participativa (2009), desloca-se para as reações do público às peças publicitárias e produtos anunciados, fator ampliado pelo caráter interativo da Internet ${ }^{15}$.

Constatou-se, portanto, que Harlan Coben, enquanto escritor contemporâneo, utiliza de elementos presentes em seu período cotidiano na construção de sua narrativa, sem se abster de citar marcas características do período retratado, ao mesmo tempo em que influencia percepções acerca de postulações que envolvem o esporte moderno, levando o leitor mais atento à possíveis associações e reflexões críticas correlacionadas à aspectos semelhantes ocorridos fora das páginas. A literatura policial, neste caso, se apresenta como uma fonte fecunda para aproximações entre o meio esportivo e a análise literária, assim como ao campo da comunicação, em particular no que tange a fatores imbricados aos espetáculos esportivos.

\section{REFERÊCIAS}

ADNEWS. Infográfico mostra quais marcas e atletas da Rio 2016 mais repercutiram nas redes. 22 de agosto de 2016. Disponível em: < http://adnews.com.br/midia/infograficomostra-quais-marcas-e-atletas-da-rio-2016-mais-repercutiram-nas-redes.html > . Acesso em: 24 de agosto de 2016.

15 A cultura da convergência, esclarecida por Jenkins (2009), utiliza-se de três elementos chaves para sua compreensão: inteligência coletiva, cultura participativa e convergência dos meios de comunicação. Este artigo demonstra as aplicações de tais elementos no campo esportivo (com mais destaque ao segundo e terceiro aspectos), porém, para abordamos tais elementos com mais assiduidade, seriam necessárias mais laudas do que dispomos no momento. Indicamos, portanto, a possibilidade de estudos futuros que relacionem demais elementos do esporte com os conceitos de Henry Jenkins. 
. Marcas encerram contrato de patrocínio com nadador Ryan Lochte. 22 de agosto de 2016. Disponível em: < http://adnews.com.br/negocios/marcas-encerramcontrato-de-patrocinio-com-nadador-ryan-lochte.html $>$. Acesso em: 24 de agosto de 2016.

AGÊNCIA FIRMA. Marketing e Publicidade: qual a diferença?. 2016. Disponível em: http://agenciafirma.com.br/marketing-e-publicidade-qual-a-diferenca/. Acesso em: 12 de junho de 2017.

BETTI, M. A Janela de Vidro: esporte, televisão e educação física. 290 f. Tese (Doutorado em Educação) - Faculdade de Educação, Universidade Estadual de Campinas, Campinas, 1997.

BOURDIEU, P. Como é possível ser esportivo?.In: BOURDIEU, P. Questões de sociologia. Rio de Janeiro: Marco Zero, 1983. p. 136-156. Disponível em: http:/www.pgedf.ufpr. br/downloads/Artigos \% 20PS \% 20Mest \% 202015/ELS/WM-Como \% 20\% C3\% A9\% 20 posss $\%$ C3\%ADvel\%20ser\%20esportivo\%20P.\%20Bourdieu.pdf. Acesso em 24 de agosto de 2016.

CANDIDO, A. Literatura e Sociedade. São Paulo, T. A. Queiroz, 2000.

CASTRO, M. L. D.; BOM, G.; JOÃO, A. G. Estudo das configurações de um garotopropaganda. In: VIII Congresso de Ciências da Comunicação da Região Sul, 2007, Passo Fundo. Anais. Passo Fundo: Intercom, 2007. Disponível em: http://www.intercom.org. br/papers/regionais/sul2007/resumos/R0125-1.pdf. Acesso em: 25 de Julho de 2016.

COBEN, H. Quebra de Confiança. São Paulo: Arqueiro, 2011. . Jogada Mortal. São Paulo: Arqueiro, 2012.

. Página Oficial Harlan Coben. Disponível em: http://www.harlancoben.com/. Acesso em: 06 de julho de 2016.

DEBORD, G. A sociedade do Espetáculo. eBooks Brasil, 2003. Disponível em: http://www. ebooksbrasil.org/adobeebook/socespetaculo.pdf. Acesso em: 24 de agosto de 2016.

DIAS, J. E. F. et al. Marketing esportivo como ferramenta de sucesso das estratégias de marketing nas empresas. Lins (São Paulo). 2009. Disponível em: http://200.159.127.206/ encontro2009/trabalho/aceitos/CC30581505808.pdf. Acesso em: 10 de junho de 2017.

FERREIRA, A.C. A fonte fecunda. In: O Historiador e Suas Fontes. PINSKY, C.B.; LUCA, T.R. (orgs). São Paulo: Contexto, 4. ed. 2015.

GIOVANNI, G.; GEBARA, A.; PRONI, M. W. Dimensões econômicas do esporte no Brasil. Campinas: Unicamp, 1995

INSTITUTO PRÓ-LIVRO. Retratos da Leitura no Brasil. $4^{\circ}$ ed. Rio de Janeiro, 2016. Disponível em: http://www.snel.org.br/wpcontent/uploads/2016/06/Pesquisa_Retratos_ da_Leitura_no_Brasil___4.pdf. Acesso em: 09 de julho de 2016.

JENKINS, H. Cultura da Convergência. 2 ed. São Paulo: Aleph. 2009.

JOÃO, A. G. Garoto Propaganda Casas Bahia: configuração e estratégia. 88 f. Dissertação (Mestrado em Ciências da Comunicação) - Programa de Pós-Graduação em Ciências da Comunicação, Universidade do Vale do Rio dos SinosSão Leopoldo, 2006. Disponível em: http://www.repositorio.jesuita.org.br/bitstream/handle/UNISINOS/2608/garoto\%20 propaganda.pdf? sequence $=1$ \&isAllowed $=y$. Acesso em: 24 de agosto de 2016 . 
KELLNER, D. A cultura da Mídia. Bauru, SP. EDUSC, 2001.

. A cultura da mídia e o triunfo do espetáculo. Líbero, n. 11, vol. 6, ano VI. 2004. Disponível em: http://www.revistas.univerciencia.org/index.php/libero/article/ view/3901/3660. Acesso em: 25 de julho de 2016.

KOTLER, P.; ARMSTRONG, G. Princípios de marketing. Trad. Arlete Fimille Marques e Sabrina Cairo. 9. ed. São Paulo: Prentice Hall, 2003.

LINS, A. No mundo do Romance Policial. São Paulo: Ministério da Educação e Saúde: Serviço de Documentação, Cadernos de Cultura, 1947. Disponível em: < https:// pt.scribd.com/doc/307690012/Alvaro-Lins-No-Mundo-do-Romance-Policial > . Acesso em: 24 de julho de 2016.

MARCHI JR, W. O Esporte "Em Cena": perspectivas históricas e interpretações conceituais para a construção de um Modelo Analítico. Revista Alesde. v. 5. n. 1. 2015. p. 46-67. MARCONDES, P. Uma História da Propaganda Brasileira. Rio de Janeiro: Ediouro: 2001. MASSI, F. O romance policial do século XXI: manutenção, transgressão e inovação do gênero. São Paulo: Cultura Acadêmica, 2011. (Coleção PROPG Digital - UNESP). ISBN 9788579832130. Disponível em: < http://hdl.handle.net/11449/109189>. Acesso em: 25 de julho de 2016.

PIRES, C. S. A tipologia do Romance Policial. Revista Garrafa (Rio de Janeiro), n. 5, janabr. 2005. Disponível em: http://www.ciencialit.letras.ufrj.br/garrafa5/6.html. Acesso em: 06 de julho de 2016.

POZZI, L. F. Os riscos do marketing esportivo. Revista RAE Light. v. 7, n. 4, p. 4-5, 2000. Disponível em: http://www.scielo.br/pdf/rae/v40n4/v40n4a13.pdf. Acesso em 09 de junho de 2017.

PRONI, M. W. Marketing e organização esportiva: elementos para uma história recente do esporte-espetáculo. Revista Conexões. Campinas: v. 1, n. 1, p. 82-94, 1998. Disponível em: https://periodicos.sbu.unicamp.br/ojs/index.php/conexoes/article/ view/8638015/5701. Acesso em: 09 de junho de 2017.

VLASTUIN, J.; ALMEIDA, B. S.; MARCH JR, W. O Marketing Esportivo na gestão do voleibol brasileiro: fragmentos teóricos referentes ao processo de espetacularização da modalidade. Revista Brasileira de Ciências do Esporte. Campinas: v. 29, n. 3, p. 9-24, 2008. Disponível em: http://oldarchive.rbceonline.org.br/index.php/RBCE/ article/view/206/210. Acesso em: 10 de junho de 2017.

Recebido em: setembro/2016

Aprovado em: junho/2017 